\title{
The Influence of Prior Expectations of a Robot's Lifelikeness on Users' Intentions to Treat a Zoomorphic Robot as a Companion
}

\author{
Maartje Margaretha Allegonda de Graaf ${ }^{1}$ • Somaya Ben Allouch ${ }^{2}$
}

Accepted: 5 February 2016 / Published online: 23 February 2016

(C) The Author(s) 2016. This article is published with open access at Springerlink.com

\begin{abstract}
We are, at our roots, social creatures who are designed to bond with others. Given that robots are expected to increasingly serve humans in social roles, insight into the psychological aspects of our relationships with robots is becoming more relevant. Earlier findings indicate a strong role of a robot's perceived lifelikeness and gender for humanrobot companionships. In an experimental study, we tested whether an individual's gender (male vs. female) and prior expectation of a robot's lifelikeness (high vs. low) influence the effect of preconditions originally identified for human friendship formation (i.e., proximity, physical attraction, similarity, reciprocal liking, intimacy) on the individual's intention to treat a zoomorphic robot as a companion. Our results show that when people have high prior expectations of a robot's lifelikeness, similar variables that explain why people establish relationships with each other are better able to explain their intentions to treat such a zoomorphic robot as a companion. Thus, companion robots should have a lifelike appearance, which does not necessarily mean a humanlike appearance. Moreover, men and women focus on different preconditions for human friendship formation when they evaluate their intentions to treat zoomorphic robots as companions. This means that developers of companion robots should be aware of these gender differences in bonding, and men and women may even prefer different designs, in terms of either appearance or behavior, for their companion robots.
\end{abstract}

\footnotetext{
Maartje Margaretha Allegonda de Graaf

m.m.a.degraaf@utwente.nl

University of Twente, Enschede, Netherlands

2 Saxion University of Applied Sciences, Enschede, The Netherlands
}

Keywords Companionship · Human-human relationships · Relationships with nonhumans · Human-robot relationships . Zoomorphic robots

\section{Introduction}

Close relationships are tremendously important to human beings. Psychologists have demonstrated the crucial role that friendships play in various aspects of life, from the development of self-identity to self-esteem, and their ability to reduce stress [82]. Given that computer technologies are increasingly interacting with us in complex and humanlike ways through robots, wearable devices, PDAs, and various other ubiquitous interfaces, the psychological aspects of our relationships with these technologies are taking on an increasingly important role [16]. In the future, robots are expected to serve humans in various social roles, such as nursing, child and elder care, and teaching environments. These socially assistive robots, in addition to their functional requirements, will also include socially interactive components [36]. In addition to performing their monitoring and assistive tasks, these robots will also need to engage in social interaction and create (trust) relationships with their users to achieve their goals (e.g., improving an elderly person's health). Establishing some form of relationship between user and robot improves the long-term acceptance of robots $[44,53]$. Investigating the factors that could explain why some people are willing to form such human-robot relationships could help to enhance the long-term acceptance of robots with the capability of social interaction.

The exploration of human-robot relationships is a fairly new field of research. With the more evident merging of the human and artificial worlds anticipated in the near future, it is becoming increasingly important to explore and under- 
stand the psychology behind human-robot relationships [62]. From human-computer interaction research, it is already known that people react to computers as if they are social actors [88]. Robots, being autonomous systems and possessing higher levels of anthropomorphism, are even more likely to be treated in a similar manner [7]. Indeed, as argued by Turkle [100], social robots are profoundly different from computer technologies, because these 'relational artifacts' demand that their users relate to them as they would to another human being. In addition to this tendency to respond socially to nonhuman objects, it has been argued that the fundamental human motivation of the 'need to belong' $[9,22]$ not only induces the desire for meaningful and enduring relationships with others but also increases the probability that people will form emotional attachments to artificial beings [56]. Envisioning a future in which the sociability of robots will only increase, it becomes ever more important to study the possible relationships human users may form with robotic others.

To date, robots still have quite limited interaction capabilities, which might create a gap between users' initial expectations of a robot and the actual experiences they gain after some preliminary interactions with that robot $[37,43,65]$. Yet, people's prior expectations regarding a robot's lifelikeness influence their evaluations of the robotic system [81]. Moreover, differences between men and women have also been observed in human-robot interaction research, including studies focusing on bonding [40,100]. Therefore, the current study investigates whether an individual's gender (male vs. female) and prior expectation of a robot's lifelikeness (high vs. low) influence the effect of the preconditions originally identified for human friendship formation on the individual's intention to treat a zoomorphic robot as a companion. The paper begins with a discussion of human-human relationships and explores the foundations of the human need to socially connect with others. Next, several insights on relationships with nonhumans will be presented based on research on human-pet relationships and people's attachments to objects. Thereafter, current knowledge regarding human-robot relationships will be presented, followed by an explanation of the necessity for further investigation of people's intentions to treat zoomorphic robots as companions considering known preconditions for human friendship formation.

\section{Human-Human Relationships}

Relationships with others lie at the very core of human existence, as humans are conceived within relationships, born into relationships, and live their lives in relationships with others [14]. There are several theoretical frameworks in social psychology that address various aspects of human relationships, one of which is the framework of the human need to belong. Baumeister and Leary [9] presented an extensive account of evidence that supports the argument that the need to belong is a fundamental human need. Based on their literature review, the authors claimed that the need to belong provides a framework for understanding and integrating most existing literature on human interpersonal behaviors, such as relationships. The need to belong is presumed to have an evolutionary basis in the use of social bonds for survival and reproductive benefits [9]. Humans living in a group can share food, find mates and assist each other in caring for offspring.

These behaviors are presumed to be the result of a set of internal mechanisms that guide individuals to seek belongingness with social groups [9]. Moreover, people need relationships characterized by frequent interpersonal contact and a feeling of mutual social bonds [82,106]. Additionally, a lack of belongingness constitutes severe deprivation and can cause a variety of ill effects [9]. Indeed, research among individuals who experience unmet belonging needs, either through randomly assigned experimental conditions or self-assessment measures, has indicated that threats to belongingness and chronic unmet belonging needs are related to greater attention to and processing of socially relevant information [41]. Moreover, individuals whose need to belong is threatened are more likely to experience social presence from nonhumans, such as television personae and pets [34], perhaps to provide them with a social outlet [41]. Thus, the human need to belong may also explain why some individuals seek social relationships with robotic others.

Although the theory of the need to belong describes the human necessity to connect with others, it lacks the ability to explain with whom we engage in relationships and with whom we do not. Therefore, we will continue to provide insight into the preconditions that influence with whom we affiliate and under what circumstances human relationships are likely to be established.

\subsection{Acquaintance}

Human relationships begin as acquaintances between two people. Proximity and physical attraction can offer explanations for why two people become acquainted [15]. An acquaintance cannot begin before one person meets another, and physical attraction is indicated as a crucial factor in first impressions [20]. Below, proximity and physical attraction will be discussed as two factors that explain the process of two individuals becoming acquainted with one another.

\subsubsection{Proximity}

One of the most powerful predictors of whether any two given people will be friends is their proximity. Randomly assigned college roommates, who are thereby forced into frequent interactions, are far more likely to become good friends than 
enemies [77]. Proximity, or, more precisely, functional distance, is a powerful predictor of liking. Functional distance is a measure of how often people's paths cross. When two individuals are in a 'closed field' situation in which people are forced to spend time together, such traveling on the same bus each morning, the environment itself causes these people to notice each other [61]. However, why does proximity breed liking? One relevant factor is availability; obviously, one has fewer opportunities to get to know someone whose path one is unlikely to cross. Proximity enables people to discover commonalities and exchange rewards. Proximity also leads to liking for another reason: mere exposure to any novel stimuli enhances people's ratings of them. The mere-exposure effect refers to this tendency for novel stimuli to be evaluated more positively after the rater has been repeatedly exposed to them. A meta-analysis shows that the mere-exposure effect is robust and reliable [18]. Proximity is rewarding. It costs less time and effort to receive the benefits of friendship with someone who lives or works close by. Proximity also creates an opportunity for acquaintance.

\subsubsection{Physical Attraction}

However, proximity is not sufficient for the establishment of human friendships. When two people are in not a closed environment but an 'open field' situation, such as a bus station, there are other factors that cause one to notice the other [13]. One such factor is physical attraction, namely, a positive evaluation of the physical appearance of another [15]. There are many research studies demonstrating the importance of physical appearance, which is regarded as a crucial factor in determining first impressions of other people [20]. This is explained by the 'what is beautiful is good' paradigm [32], which refers to the presumption that physically attractive people (or things) also possess other socially desirable traits. To say that attractiveness is important, other things being equal, is not to say that physical appearance always outranks other qualities. However, first impressions are important and are becoming more so as societies become increasingly mobile and urbanized and as contacts with other people become more fleeting [68]. We like attractive people because we associate them with other desirable traits $[1,55]$.

\subsection{Friendship Maintenance}

As people come to know one another, other factors begin to influence whether an acquaintance will develop into a friendship. The factors that determine initial attraction are different from those that determine prolonged friendship. Although proximity and physical attraction are the gatekeepers for interaction [15], research suggests that there are characteristically different stages of attraction, that different types of cues are attended to at different stages of attraction, and that cues may lose their force as an acquaintance develops [99]. Cues related to friendship formation are considered to shift from physical characteristics to those immediately concerned with more cognitive attributes [30]. At this stage, people begin to select those individuals with whom friendship is assumed to be desirable. This is when one begins to evaluate the other's personality and personal characteristics in terms of comparison with one's own.

\subsubsection{Similarity}

Given that two people do come to know one another, further factors will influence whether their acquaintance develops into a friendship. The factors that determine initial attraction are different from those that determine prolonged friendship [29]. The cues related to friendship formation are considered to shift from physical characteristics to those immediately concerned with more cognitive attributes [28]. This is when people begin to select those individuals with whom friendship is assumed to have a positive appeal. This is also the stage at which one concerns oneself with means of describing the other's personality and personal characteristics. Each individual also evaluates the other's personality in terms of its overlap with that individual's own personality, i.e., their similarity.

The formulation of the similarity-attraction hypothesis is drawn from Newcomb's [77] well-known paper on the prediction of interpersonal attraction. In this hypothesis, similarity (real or perceived) of personality is considered to be a major determinant of likeability and friendship choice [70]. Since Newcomb's discovery, research has repeatedly demonstrated that the more similar someone's attitudes are to one's own, the more likeable one will find that person. Likeness generates liking. Research on liking and attraction has shown that we tend to like others who are similar to us [4] because they provide us a source of validation for ourselves. This provides the basis for the next precondition for human friendship formation, reciprocal liking.

\subsubsection{Reciprocal liking}

Proximity and attractiveness influence one's initial attraction to someone else, and the discovery of similarities helps people to progress through the various stages of relationship development $[74,99]$. Similarity between attitudes, in particular, is related to reciprocal liking $[4,20,77]$. If others have similar opinions, we feel rewarded because we presume that they like us in return [90]. The phenomenon of reciprocal liking is grounded in Heider's [48] balance theory: we like those who like us, or those who like the same things that we like (one of which is ourselves). Thus, liking is typically mutual, i.e., reciprocal liking. However, reciprocal liking depends not only on one believing oneself to be likable [51] but also on 
the sequence in which liking and disliking may have been expressed [3]. Furthermore, not only the liking itself but also the reasons for it are subject to interpretation [51]. The explanatory power of reciprocal liking seems, therefore, to have its limitations.

Reciprocal liking also occurs when people interact with technologies. People who have been flattered by their computers report more positive affect, better performance, more positive evaluations of the interaction, and more positive regard for the computers [88]. Flattery can thus be an effective strategy for social robots to encourage their users to like them. For example, in the studies of Leite and colleagues $[59,60]$, it was found that children preferred to receive esteem support (i.e., reinforcement of the other's sense of competence) from the robots with which they interacted and evaluated those robots that provided positive feedback more positively.

\subsubsection{Intimacy}

Researchers agree that intimacy is essential for many human friendships [58], such as human friendships. Intimacy results from a dynamic, interpersonal process in which both selfdisclosure and partner responsiveness are key components [89]. Self-disclosure is the verbal communication of personally relevant information, thoughts, and feelings to another, and research on self-disclosure often relies on the degree or depth of self-disclosure as an index of intimacy [99]. In the context of self-disclosure, scientists have distinguished between factual and emotional disclosure [89]. Factual self-disclosures reveal personal facts and information, and emotional self-disclosures reveal one's private feelings, opinions and judgments. Emotional self-disclosures are believed to create greater intimacy because they provide the listener with the opportunity to support and confirm core aspects of the discloser's view of self [89]. Trust in the listener will enhance self-disclosure [47]. However, the assertion of a causal relation between self-disclosure and growing intimacy has been criticized [83]. It could be that a person may reveal private information merely to express him- or herself, to release tension, or to gain relational control, which does not necessarily imply that this individual is seeking or will achieve a more intimate bond with his or her partner.

Other researchers advocate the need to evaluate selfdisclosure together with the level of partner responsiveness to assess the level of intimacy $[11,27]$. Perceived partner responsiveness is the belief that a relationship partner understands, values, and supports important aspects of the self [89]. A positive evaluation of partner responsiveness leads to security and enjoyment, whereas a negative evaluation leads to anxiety and distress [47]. Therefore, an integrated model of intimacy has been developed by Reis and Shaver [89], who describe intimacy as the product of a transactional, interpersonal process whereby an individual discloses personal information, thoughts, and feelings to a partner; receives a response from that partner; and interprets that response as understanding, validating, and caring.

The integrated model of intimacy is supported by the principle of the depth of penetration from social penetration theory. The depth of penetration refers to the degree of intimacy, which increases when a human friendship develops to a more personal level. According to social penetration theory [99], self-disclosure is reciprocal. Vulnerability shown by an individual elicits trust, which, in turn, evokes a need for emotional equity that could be fulfilled by self-disclosure from that individual's partner. Consequently, intimacy grows through interactions in which an individual discloses personal information, thoughts and feelings to a partner. In return, the partner responds in a way that is perceived by the individual as understanding, validating and caring.

\section{Relationships with Nonhumans}

People are capable not only of forming relationships with other humans but also of engaging in social relationships with nonhumans. In this section, we will address people's relationships with their pets and further explore people's attachments to objects. Additionally, we will reflect on how this knowledge can be used to study the relationships individuals might establish with robots.

\subsection{Human-Pet Relationships}

We share our planet with an astounding variety of different animals, but we have selected only a minority to hold the privileged position of pets. Moreover, among these pets, merely a few have been considered for companionship [95]. A pet may serve as a substitute for caring, with people treating it as a child; a substitute for security, with people treating it as a parent; or a substitute for companionship, with people treating it as a partner [2]. Indeed, surveys addressing human-pet relationships $[46,84,85]$ have reported that people exhibit feelings and actions that portray their pets as legitimate participants in social interaction. These surveys show that people report that they can understand their pets' language and that their pets understand human language, as well, and these people form intimate bonds with their pets, sometimes stronger than those developed with friends and family members.

People have owned pets since the dawn of humanity. Currently, people expend considerable affection and money on their pets, which, from a Darwinian perspective, is a questionable form of behavior [2]. As described above, the evolutionary significance of attachments formed with other humans is clear. However, in the case of human-pet relationships, the question is raised of why people should form similar attachments with members of a different species. 
Such an attachment involves taking care of a member from another species, with no apparent benefits obtained from taking on this responsibility. According to Serpell [95], there are two main reasons why people may treat pets as companions. First, such pets have been part of our natural environment for thousands of years, since our ancestors began domesticating these animals, and thus have had plenty of time to adapt to their role of companion. Second, they possess certain qualities that make them especially suitable and desirable as animal companions, including their daily routine, their height, their considerable pleasure in physical attention and their apparent signs of friendship [95].

In addition to these qualities, Archer [2] argues that pets achieve their evolutionary position in human life because of their ability to adapt to the human way of life [95]; their similarity to humans in terms of emotions and moods, although these are expressed differently [64]; their capability for showing affection to their owners [96]; and their historical availability as pets [69]. By virtue of these combined qualities, pets persuade us that they love and understand us, despite all our manifest deficiencies and failures. Although compared with a relationship with another person, the human-pet relationship might seem shallow, at least a pet's affection for us is reliable and unconditional [95]. Moreover, because of our ability to assign humanlike attributes to nonhuman objects [34], we are able to bridge the extreme gap between humans and animals in terms of language and thoughts.

\subsection{Attachment to Objects}

Most people are unaware of the relationships they have with the objects in our lives. Our favorite objects in our houses are those with attachments to certain people or particular times in our lives [86]. Looking back to childhood, most people can remember something with symbolic meaning. Every object has its own individual story, and utilitarian aspects are no longer the primary reasons for buying an object. If users associate a product with real human emotions, their interaction with it goes beyond the satisfaction of an emotional hit, and they engage in an emotional rapport with that object, turning it into a living being [86]. People who have become emotionally attached to a technology perceive its usability more positively and have higher intentions to continue to use that technology in the future $[98,108]$. Thus, emotional attachment can lead to greater acceptance of technologies such as social robots.

\subsection{Treating Zoomorphic Robots as Companions}

The great question remains: could we also form relationships with zoomorphic robots? We define the concept of humanrobot relationship as a human user's intention to perceive or treat a robot as a companion. Given that computer tech- nology is increasingly interacting with us through complex and humanlike interfaces, the psychological aspects of our relationships with these interfaces are taking on an increasingly important role [16]. When such technologies present explicit cues of identity or social agency, it is not unlikely that humans will treat these entities as social actors [88]. It is expected that this effect may even be magnified in the case of embodied agents that interact socially using natural language and non-verbal behaviors. Indeed, research shows that people tend to ascribe human-like properties, characters, and mental states to socially interactive robots [52]. Moreover, preliminary research insights indicate that people are not only capable of building relationships with robots [44,53,54], but can also benefit from those relationships $[6,50,103]$. However, this bonding depends on various aspects of the robots, indicating that people do not bond with just any object. Nevertheless, very simple interactions with robots can already seduce people into engaging with them.

\subsubsection{How nonhumans can satisfy our need to belong}

The literature described here suggests that nonhumans play a more prominent and more active role in the interactions of humans with their social environments than previously acknowledged by sociologists [23]. Because people interact similarly with social interfaces as they do with other people $[54,88]$ and seemingly build relationships following the same rules as for human-human interactions $[6,16]$, it seems unnecessary to depart from these human-human interaction rules when evaluating human-robot interactions [57]. Therefore, it is assumed that there will be more similarities than differences between human-human interactions and humanrobot interactions. Moreover, these similarities are needed to create meaningful interactions and relationships between humans and robots [26]. Thus, if these premises hold true in future human-robot interaction research, then the fundamentals of human-human interpersonal interactions should serve as the point of departure for the development and implementation of social behavior for robots.

The theory of the need to belong predicts that humans are, in principle, capable of bonding with robots given the precondition that these robots are sufficiently social to satisfy the needs of such a relationship with respect to regular and meaningful interactions [57]. People tend to ascribe human characteristics to nonhuman objects [88], and this challenges the restriction of meaningful social interaction to interactions with minded human beings. Certain interactionists, e.g., [91,105], have argued that humans can project mind onto nonhumans-including animals, objects and imagesseemingly endowing them with human capacities. Similarly, the process of the media equation allows humans to perceive nonhumans as viable others in social interactions. This make it irrelevant for nonhumans to actually possess the 
human capacities traditionally defined as critical for social interaction [23]. Overall, this reasoning argues for the inclusion of nonhumans in meaningful social interaction. Thus, robots endowed with capacities perceived by humans as social behavior could easily pass as legitimate partners in social interactions with humans.

\subsubsection{Similarities between pets and robots}

However, considering that we used a zoomorphic robot in this study, we should also reflect on human-pet relationships. Using a robot with a zoomorphic embodiment has the advantage that the 'uncanny valley effect' can be better avoided [38]. The 'uncanny valley effect' is a hypothesis that predicts that robots with human-like characteristics look and act almost, but not perfectly, like actual human beings, causing a revulsion response in human observers [76]. Moreover, robots with an animal-like design rely on the assumption that familiar appearance and communication modes easily and effectively support human-robot interactions [92]. Robots with zoomorphic embodiments exhibit characteristics that are associated with domesticated animals and are designed to imitate those of living creatures to establish human-robot relationships, which are, in many ways, similar to owner-pet relationships [54]. Thus, it was desirable to use a robot with a zoomorphic embodiment in this study. Although humans and animals differ in many aspects, such as language, learning and culture, analogies with human-human interrelationship theories, such as attachment theory $[2,109]$, have nevertheless helped to explain a large number of human-pet attachment studies [90]. Moreover, the relationships people can form with their pets [2] show us that satisfying interspecies communication is possible. Thus, even though the robot used in this study was not humanoid but rather zoomorphic, we assumed that we could still build on theories of human-human relationships to explain why people are willing to treat a zoomorphic robot as a companion.

Because people exhibit similar behaviors of assigning humanlike attributes to robots as they do to other animals and objects, human-robot relationships-even with pet-like robots-might similarly develop. Indeed, there are several similarities in how we relate to animals and robots. These similarities suggest that among other things, it is the appearance of the robot or animal, and not their ontological status, that determines how we treat them. These similarities are related to how we perceive both types of entities in different contexts, such as their functionality in society and between societies or cultures [24]. Regarding functionality, both animals and robots appear in various roles. For example, we have multiple different relationships with animals: as companions or pets; as living meat, livestock, and production units or farm animals; as game for hunting; as wild animals; as experimental material in scientific experiments; and as entertainment in the zoo [45,104]. Similarly, we treat robots differently depending on the different use contexts in which they appear. For example, we treat robots as slaves in an industrial context but can more easily perceive them as companions when they interact socially with us in our home environments. In addition to the use context, Coeckelbergh [24] notes the similarity of different views on animals and robots with regard to cultural differences. For example, in certain cultures, dogs are regarded as food, whereas in our Western society, dogs are treated as companions. Similarly, there seems to be a cultural difference in how cultures perceive robots [67]; Western countries appear to be dominated by slave models of robots, whereas Eastern countries are more familiar with treating robots as companions. Thus, the manner in which we relate to both animals and robots depends on their appearance. This means that how we regard both types of entities depends on our human perception, which, in turn, depends on personal, contextual and cultural categories [24]. Human-robot relationships should not be understood in relation to what the robot actually can or cannot do but should rather be approached in terms of how they appear to us and how we perceive them in these relationships.

Thus, it might be that social robots, even pet-like ones, are just as capable as other human beings of satisfying the human need to belong. So, there is a need for a further exploration of the role of robot companions in society and the value placed on relationships with them. Some researchers state that the ability to develop and maintain individual relationships may be a useful benchmark for human-robot interaction and that robots should be able to maintain relationships with people that are unique, individual, and personal [66]. Given that robots are predicted to increasingly serve in social roles for which some form of human-robot relationship would be beneficial, this study will investigate whether the preconditions for human friendship formation can explain why people may treat zoomorphic robots as companions.

\section{Gender and Prior Expectations in Human-Robot Interaction}

Because both prior expectations and gender have been found to influence the results of human-robot interaction studies, these two factors will be further discussed below to formulate the hypotheses for the study presented in this paper.

\subsection{Prior Expectations of a Robot's Lifelikeness}

Individuals' prior expectations regarding a robot could influence their evaluations of that robot. Previous human-robot interaction research has shown that people with high prior expectations of a robot's lifelikeness are more likely to be disappointed in their interactions with that robot compared 
with people with low prior expectations [81]. Lifelikeness is related to Bartneck et al.'s [8] concept of animacy, which resembles the degree to which users believe that a robot behaves and responds realistically. Several studies have indicated that a more animate robot leads to improved human-robot interactions [8] and that users are more willing to perceive such a robot as a friendly companion [63]. These results indicate that a user's prior expectation of a robot's lifelikeness might play a role in the formation of human-robot companionships.

To date, robots still have quite limited interaction capabilities, which might create a gap between users' initial expectations of a robot and the actual experiences they gain after some preliminary interactions with that robot [65]. In one of our previous studies investigating the long-term acceptance of robots in real homes [43], the participants encountered such an expectation gap, which caused several participants with high prior expectations of the robot's capabilities and sociability to stop using the robot before the end of the study. Similar results were also found by Fernaeaus et al. [37], whose participants also stopped using their robots because they held high prior expectations about the robot's social and learning behavior that were not fulfilled. Prior expectations have also been determined to play an important role in human-human interactions [17]. Given that people react similarly to robots as they do to living mammals [54], it could be that this reaction increases people's expectations of a robot's abilities to behave as a lifelike social agent [107]. This study therefore focuses on individual's prior expectations about a robot's lifelikeness.

Two theories that could help explain the influence of people's prior expectations on behavioral outcomes are those of self-fulfilling prophecy and confirmation bias. The concept of self-fulfilling prophecy describes how (social) expectations influence the manner in which people interact with one another [71]. High prior expectations of another person cause us to initially evaluate that other person as more capable than we do when our prior expectations are set low. Confirmation bias refers to the tendency for humans to seek or interpret evidence in such a way that it will support someone's beliefs or prior expectations [78]. Based on these theories, it can be hypothesized that people with high prior expectations of a robot will tend to focus on evidence from their interactions with that robot that supports their expectations, which, in turn, will make them evaluate that robot more positively than will people with low prior expectations. Regardless of the form that influence takes, prior expectations could potentially influence people's intentions to treat robots as companions, and thus, such expectations are a vital determinant for further investigation. Based on the existing knowledge, the following hypotheses were formulated:
H1a: People with high prior expectations of a robot's lifelikeness will evaluate the robot more positively with regard to companionship.

H1b: People with high prior expectations of a robot's lifelikeness will evaluate the robot more positively with regard to the preconditions for human friendship formation.

H1c: The preconditions for human friendship formation will better explain people's intentions to treat robots as companions under conditions of high prior expectations.

\subsection{Gender Effects in Human-Robot Interaction}

Psychology research indicates gender differences in the schematic processes of decision making [10]. Indeed, gender differences play a role in the acceptance and use of technological devices, because of the differences between males' and females' social behavior and their social roles in society [80]. Gender differences in the perception of technology have been found in the evaluation of these systems [97,101], the perceived social influence to use or buy a technology $[31,73,75]$, and in the user's self-evaluation of their technical skills enabling them to use that technology [101]. Differences between men and women have also been observed in human-robot interaction research. When evaluating robot technologies in general, compared with men, women are more skeptical and afraid of becoming dependent on robots [93], and they are less likely to accept robotic technologies in their daily lives [5]. In the evaluation of humanoid robots, women also tend to be more negative than men. Women have been found to rate a humanoid robot more negatively, to be more anxious to interact with it [42] and to anthropomorphize it less than men [94]. However, when the robot in question has a zoomorphic appearance, women tend to be more positive than men. In the evaluation of zoomorphic robots, women perceive a rabbit-shaped robot as having higher selfpresentational potential and as being more useful [33], are more likely to follow the advice of a catlike robot [102], and are more willing to form human-robot relationships with robotic seals $[40,100]$. The existence of gender differences in human-robot interaction studies motivated further investigation on this topic in the current study. Based on the existing knowledge, the following hypotheses were formulated:

H2a: Women will evaluate a zoomorphic robot more positively with regard to companionship.

H2b: Women will evaluate a zoomorphic robot more positively with regard to the preconditions for human friendship formation. 


\section{Box 1 Text on the instruction sheet}

The robot you are going to meet ...(A). Its name is Pleo, and it resembles a ...(B). Pleo ...(C), and it ...(D). This means that it can perform ...(E) tasks and ...(F) from its interactions with you. Pleo can ...(G) and be ...(H), and it has ...(I) ways it can move. Pleo has ...(J) possibilities for communication, for example ...(K) sounds and body movements. The way Pleo moves is ...(L) because its internal motors ...(M). It has ...(N) speakers with which it can ...(O), just like a ...(P). In addition, Pleo has sensors ...(Q) through which it can sense ...(R) of your touch. In short, Pleo is ...(S) social robot with ...(T) technologies, which offers ...(U) interaction possibilities

H2c: The preconditions for human friendship formation will better explain women's intentions to treat zoomorphic robots as companions.

\section{Method}

\subsection{Experimental Design}

In a between-subject experiment, we tested whether an individual's gender (male vs. female) and prior expectations of a robot's lifelikeness (high vs. low) influence the effect of preconditions originally identified for human friendship formation on their intentions to treat a zoomorphic robot as a companion. The two expectation conditions were defined through manipulation of the description of the lifelikeness of the robot on the instruction and information sheet provided to each participant before interaction with the robot. The text of the instruction sheet is presented in textbox 1, and the differences in wording regarding the robot's lifelikeness for both conditions are provided in Table 1.

\subsection{Zoomorphic Robot}

The robot used in this study was the zoomorphic robot Pleo (see Fig. 1), which looks like a small dinosaur and is approximately the size of a cat. It can act autonomously, explores and reacts to its environment, interacts with its users and expresses emotions. The skin of Pleo consists of a material with a rubber texture that covers a mechanical frame. Pleo runs on fourteen different motors that are placed in different segments of its body. These motors enable it to shake its tail, bend its neck in various directions, control its mouth and eyelids, and walk slowly. Pleo is capable of making several different sounds to support its expression of feelings. It also has many different sensors distributed over its body, including eight capacitive touch sensors, two infrared (IR) sensors and a small CMOS camera, most of which are mounted on the back and head area. The robot operates fully autonomously using its standard built-in personality and behavior software.
Table 1 Manipulated phrasings for the two expectation conditions

\begin{tabular}{|c|c|c|}
\hline Position & High prior expectation & Low prior expectation \\
\hline A & $\begin{array}{l}\text {...was recently introduced } \\
\text { on the consumer market... }\end{array}$ & $\begin{array}{l}\text {...has been on the market } \\
\text { for some years... }\end{array}$ \\
\hline B & ...lifelike pet... & ...moving stuffed animal... \\
\hline $\mathrm{C}$ & ...acts autonomously... & $\begin{array}{l}\text {...cannot act } \\
\text { autonomously... }\end{array}$ \\
\hline $\mathrm{D}$ & $\begin{array}{l}\text {...reacts limitlessly to your } \\
\text { actions... }\end{array}$ & $\begin{array}{l}\text {...responds to your actions } \\
\text { in a limited way... }\end{array}$ \\
\hline $\mathrm{E}$ & ...many... & ...a few... \\
\hline $\mathrm{F}$ & ...learns... & ...cannot learn... \\
\hline G & ...communicate with you... & ...produce some sounds... \\
\hline $\mathrm{H}$ & ...raised... & ...nurtured... \\
\hline I & ...infinite... & ...limited... \\
\hline $\mathrm{J}$ & ...many... & ...a few... \\
\hline $\mathrm{K}$ & ...pet... & ...stuffed animal... \\
\hline $\mathrm{L}$ & ...limitless and lifelike... & ...limited and rigid... \\
\hline M & $\begin{array}{l}\text {...offer considerable } \\
\text { capacity... }\end{array}$ & $\begin{array}{l}\text {...do not offer sufficient } \\
\text { capacity... }\end{array}$ \\
\hline $\mathrm{N}$ & ...multiple... & ...two... \\
\hline $\mathrm{O}$ & $\begin{array}{l}\text {...produce certain } \\
\text { pre-installed sounds... }\end{array}$ & $\begin{array}{l}\text {...freely communicate with } \\
\text { you... }\end{array}$ \\
\hline $\mathrm{P}$ & ...real-life pet... & ...stuffed animal... \\
\hline Q & $\begin{array}{l}\text {...throughout its entire } \\
\text { body... }\end{array}$ & $\begin{array}{l}\text {...in a few positions on its } \\
\text { body... }\end{array}$ \\
\hline $\mathrm{R}$ & ...all... & ...some... \\
\hline $\mathrm{S}$ & ...a modern... & ....an outmoded... \\
\hline $\mathrm{T}$ & ...the newest... & ...old... \\
\hline $\mathrm{U}$ & ...very lifelike... & ...some nice... \\
\hline
\end{tabular}

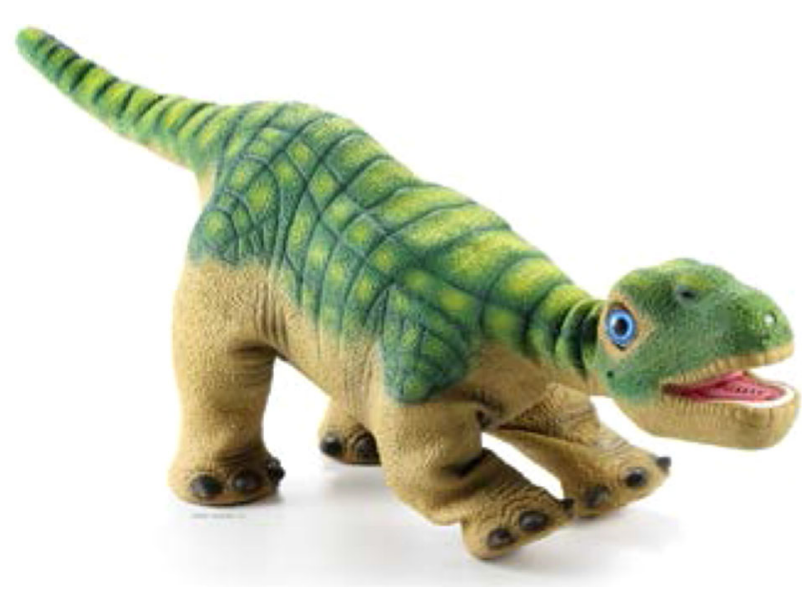

Fig. 1 Pleo, the robotic dinosaur

\subsection{Procedure}

Because previous experiences can exert influence, only participants who had never interacted with a robot before could take part in the study. First, the participants completed a 
Table 2 Variable means and SD of each of the variables for the two experimental conditions

\begin{tabular}{llllll}
\hline Variable & \multicolumn{2}{l}{ High expectation } & & \multicolumn{2}{c}{ Low expectation } \\
\cline { 2 - 3 } \cline { 5 - 6 } & $M$ & $S D$ & & $M$ & $S D$ \\
\hline Companionship & 3.78 & 1.40 & & 3.35 & 0.88 \\
Attractiveness & 5.75 & 0.92 & & 5.23 & 0.80 \\
Similarity & 0.38 & 0.74 & & 0.65 & 0.59 \\
Intimacy & 4.45 & 1.18 & & 3.87 & 0.95 \\
Animacy & 4.43 & 0.99 & & 3.60 & 0.67 \\
\hline
\end{tabular}

Similarity is higher when value is closer to zero

questionnaire to assess their personalities. Afterward, the participants were briefed about the study, in which they were allowed to interact freely with the robot for approximately $10 \mathrm{~min}$. The choice of free interaction over task-based interaction was made to allow the participants sufficient freedom to interact with the robot in their own ways and to avoid disappointment. It was assumed that a task-based interaction could lead to greater disappointment when participants failed to perform a specific task; therefore, free interaction was thought to be a superior approach. Most participants interacted with the robot by stroking it, playing with it and attempting to feed it. Before the interaction, the participants were first required to read the information and instruction sheet, thereby setting their prior expectations of the robot's lifelikeness either high or low. After interacting with the robot, the participants completed a second questionnaire in which they rated the lifelikeness of the robot and assigned a personality to the robot, along with the constructs of physical attraction, reciprocal liking, intimacy and companionship.

\subsection{Measurements}

To evaluate the preconditions for human-robot relationships, we used existing validated questionnaire items from human relationship research to evaluate each participant's intention to treat zoomorphic robots as companions. All items in the questionnaire were presented on 7-point Likert scales. Table 2 displays the mean scores of each variable for the two experimental conditions.

To check the appropriateness of the experimental conditions regarding the participants' prior expectations of the robot's lifelikeness, Bartneck et al.'s [8] measurement for animacy was administered with six semantic differentials (e.g., mechanical vs. organic), which yielded a reliable scale $(\alpha=.70)$.

The participants' intentions to treat the robot as a companion were measured using a modified version of McCroskey et al.'s [70] measurement for social attraction with four items (e.g., I think this robot can be a friend of mine), which yielded a reliable scale $(\alpha=.86)$. This variable will be referred to in the paper as companionship.

Attractiveness was measured using a modified version of McCroskey et al.'s [70] measurement for physical attraction with four items (e.g., I think this robot looks quite pretty), which yielded a reliable scale $(\alpha=.85)$.

Similarity was measured with a focus on the similarity between the personality of the participant and the participant's perception of the robot's personality. For both the participants and the robot, personality was measured using the Dutch version of the Big Five personality inventory, developed by Denissen et al. [28], which contains five personality traits: extraversion, agreeableness, conscientiousness, emotional stability, and openness. To measure similarity, a latent variable was constructed by subtracting the sum of all Big Five personality inventory scores ascribed to the robot from the participant's own personality (i.e., also the sum of all Big Five personality inventory scores). Given that earlier studies have emphasized the greater impact of subjective similarity compared with objective similarity on interpersonal attraction $[25,49]$, allowing the participants to describe the robot's personality traits seemed to be an appropriate means of measuring similarity. All scales for the personality factors were reliable (i.e., for extraversion, participant $\alpha=.83$ and robot $\alpha=.68$; for agreeableness, participant $\alpha=.71$ and robot $\alpha=.74$; for conscientiousness, participant $\alpha=.72$ and robot $\alpha=.72$; for emotional stability, participant $\alpha=.78$ and robot $\alpha=.79$; and for openness, participant $\alpha=.69$ and robot $\alpha=.88$ ).

Intimacy was measured using a modified version of the scale reported by Laurenceau and Feldman Barret [58], which contained three items regarding the participant's selfdisclosure (e.g., how much did you disclose your thoughts to the robot?), three items regarding the participant's evaluation of the self-disclosure of the robot (e.g., how much did the robot disclose its thoughts and feelings?), and three items regarding the participant's evaluation of the responsiveness of the robot (e.g., to what degree did you feel understood by the robot?). These items yielded a reliable scale $(\alpha=.70)$.

The measurement for reciprocal liking was also adopted from Laurenceau and Feldman Barret [58] and contained two questions: (1) Do you like the robot? and (2) Do you think the robot likes you? Reciprocal liking was confirmed when the participant indicated that they both liked each other.

\subsection{Participants}

A total of 86 respondents ( 41 men and 45 women, aged $M=25.76$ and $S D=7.42$ ) participated in this study. To ensure a reasonably homogeneous group, the participants were recruited from within the faculty of behavioral sciences at a university in the Netherlands. Gender was equally distributed over both experimental conditions $\left(\chi^{2}=\right.$ 
$0.047, p=.829)$, with 21 men and 22 women in the lowprior-expectation group and 20 men and 23 women in the high-prior-expectation group.

\section{Results}

\subsection{Manipulation Check}

To check whether the participants in the high-priorexpectation group actually held higher prior expectations regarding the robot's lifelikeness than the participants in the low-prior-expectation group, an independent-samples $T$ test was performed on the animacy variable. The results showed that the participants' prior expectations about the robot's lifelikeness differed significantly $(t=-4.564, p<.001)$. The participants in the high-prior-expectation group perceived the robot as more lifelike $(M=4.43, S D=0.99)$ than the participants in the low-prior-expectation group $(M=3.60$, $S D=0.67)$. This means that the manipulation of the participants' prior expectations of the robot's lifelikeness by means of the information and instruction sheet was appropriate.

\subsection{The Evaluation of Companionship}

To investigate H1a and H2a, a two-way ANOVA was performed to investigate the effect of the participants' prior expectations versus gender on their intentions to treat robots as companions. The results indicate no significant difference between gender groups $(F(3,82)=1.244, p=.268)$ or prior-expectation groups $(F(3,82)=3.068, p=.084)$ nor any significant interaction effect $(F(3,82)=0.599, p=$ .441) for these measures. It was expected that the intention to treat robots as companions would be more positive in people with high prior expectations of the robot's lifelikeness (H1a) and by women (H2a). However, the above results demonstrate that there were no statistically significant differences associated with gender or prior expectation in the participants' intentions to treat robots as companions. Therefore, hypotheses $1 \mathrm{a}$ and $2 \mathrm{a}$ were rejected.

\subsection{The Evaluation of the Preconditions of Human Friendship Formation}

To investigate $\mathrm{H} 1 \mathrm{~b}$ and $\mathrm{H} 2 \mathrm{~b}$, a series of two-way ANOVAs for the ratio scales and two separate chi-square tests for the nominal scales were performed. An initial two-way ANOVA was performed to investigate the effect of the participants' prior expectations versus gender on attractiveness. The results indicate no significant difference between gender groups $(F(3,82)=0.424, p=.517)$ nor any significant interaction effect $(F(3,82)=2.285, p=.134)$ for attractiveness. However, the participants' prior expectations did have a sig-
Table 3 Similarity evaluations from men and women for both expectation conditions

\begin{tabular}{llllll}
\hline Similarity & \multicolumn{2}{l}{ High expectation } & & \multicolumn{2}{c}{ Low expectation } \\
\cline { 2 - 3 } & $M$ & $S E$ & & $M$ & $S E$ \\
\hline Men & 0.44 & 0.15 & & 0.91 & 0.14 \\
Women & 0.33 & 0.14 & & 0.40 & 0.15 \\
\hline
\end{tabular}

nificant effect regarding attractiveness $(F(3,82)=8.314$, $p=.005$, partial $\left.\eta^{2}=.09\right)$. Participants with high prior expectations of the robot's lifelikeness evaluated the robot as more attractive than participants with low prior expectations (see Table 2).

A second two-way ANOVA was performed to investigate the effect of the participants' prior expectations versus gender on similarity. The results indicate that the participants' prior expectations did not have a significant effect on similarity $(F(3,82)=3.765, p=.056)$, nor was there a significant interaction effect $(F(3,82)=2.008, p=.160)$ for similarity. However, there was a significant gender effect $\left(F(3,82)=4.750, p=.0329\right.$, partial $\left.\eta^{2}=.06\right)$ with regard to similarity. Women evaluated the robot as more similar to themselves than did men in both conditions (see Table 3).

A third two-way ANOVA was performed to investigate the effect of the participants' prior expectations versus gender on intimacy. The results indicate no significant difference between gender groups $(F(3,82)=0.125, p=.724)$ nor any significant interaction effect $(F(3,82)=0.123, p=$ .727) for intimacy. However, the participants' prior expectations did have a significant effect with regard to intimacy $\left(F(3,82)=6.169, p=.015\right.$, partial $\left.\eta^{2}=.07\right)$. Participants with high prior expectations of the robot's lifelikeness evaluated the robot as offering more intimacy than did participants with low prior expectations (see Table 2).

Additionally, two separate chi-square tests were performed to investigate the effect of the participants' prior expectations of the robot's lifelikeness and the effect of gender on reciprocal liking (see Tables 4 and 5). The results show no significant difference with regard to reciprocal liking in the distributions for the two experimental conditions $\left(\chi^{2}=2.324, p=.127\right)$ nor those for the two genders $\left(\chi^{2}=0.025, p=.875\right)$.

It was expected that the preconditions for human friendship formation would be more positively evaluated by people with high prior expectations of the robot's lifelikeness (H1b) and by females $(\mathrm{H} 2 \mathrm{~b})$. The above results show that high prior expectations did result in higher evaluations of the robot's attractiveness and the perceived intimacy. Therefore, hypothesis H1b was partially supported. The results with respect to gender differences show that in both experimental conditions, women evaluated only similarity more highly compared with men. No gender differences were observed for the other pre- 
Table 4 Distributions of reciprocal liking for both expectation conditions

\begin{tabular}{llcc}
\hline \multicolumn{2}{l}{ Reciprocal liking } & \multicolumn{2}{c}{ Expectation } \\
\cline { 3 - 4 } & & High & Low \\
\hline Yes & Count & 28.0 & 21.0 \\
& Expected & 24.5 & 24.5 \\
& Std. residuals & 0.7 & -0.7 \\
No & Count & 15.0 & 22.0 \\
& Expected & 18.5 & 18.5 \\
& Std. residuals & -0.8 & 0.8 \\
\hline
\end{tabular}

Table 5 Distribution of reciprocal liking for gender

\begin{tabular}{llcr}
\hline \multicolumn{2}{l}{ Reciprocal liking } & \multicolumn{2}{l}{ Gender } \\
\cline { 3 - 4 } & & Male & Female \\
\hline Yes & Count & 23.0 & 26.0 \\
& Expected & 23.4 & 25.6 \\
& Std. residuals & -0.4 & 0.4 \\
No & Count & 18.0 & 19.0 \\
& Expected & 17.6 & 19.4 \\
& Std. residuals & 0.4 & -0.4 \\
\hline
\end{tabular}

Table 6 Regressions for companionship on the entire sample

\begin{tabular}{lcrl}
\hline Variable & \multicolumn{3}{l}{ Companionship } \\
\cline { 2 - 4 }$\beta$ & \multicolumn{1}{l}{$t$} & \multicolumn{1}{l}{$p$} \\
\hline Attractiveness & .122 & 1.459 & .149 \\
Intimacy & .391 & 4.083 & .000 \\
Similarity & -.245 & -3.307 & .001 \\
Reciprocal liking & .327 & 3.379 & .001 \\
\hline
\end{tabular}

conditions. Therefore, hypothesis $\mathrm{H} 2 \mathrm{~b}$ was only partially supported.

\subsection{Preconditions for Human Friendship Formation with Regard to Companionship}

To investigate $\mathrm{H} 1 \mathrm{c}$ and $\mathrm{H} 2 \mathrm{c}$, a series of stepwise multiple regressions were performed. An initial analysis was performed on the entire sample (see Table 6). Together, intimacy $(\beta=.391, t=4.083, \mathrm{p}<.001)$, similarity $(\beta=-.245, \mathrm{t}=$ $-3.307, \mathrm{p}=.001)$, and reciprocal liking $(\beta=.327, \mathrm{t}=3.379$, $p=.001)$ explained $58 \%$ of the variance in companionship $(F(3,82)=40.311, p<.001)$.

In a second round of regression analyses, we controlled for the experimental conditions and found different regression models (see Tables 7 and 8). For participants with low prior expectations of the robot's lifelikeness, only $33 \%$ of the variance in companionship $(F(2,40)=11.279, p<.001)$ was
Table 7 Regressions for companionship on the low-expectation group

\begin{tabular}{lcrl}
\hline Variable & \multicolumn{3}{l}{ Companionship } \\
\cline { 2 - 4 } & $\beta$ & \multicolumn{1}{l}{$t$} & \multicolumn{1}{l}{$p$} \\
\hline Attractiveness & .113 & 0.818 & .418 \\
Intimacy & .325 & 2.294 & .041 \\
Similarity & -.044 & -0.324 & .748 \\
Reciprocal liking & .353 & 2.294 & .027 \\
\hline
\end{tabular}

Table 8 Regressions for companionship on the high-expectation group

\begin{tabular}{lcrl}
\hline Variable & \multicolumn{3}{l}{ Companionship } \\
\cline { 2 - 4 } & $\beta$ & $t$ & $p$ \\
\hline Attractiveness & .165 & 1.649 & .107 \\
Intimacy & .244 & 1.932 & .061 \\
Similarity & -.391 & -4.487 & .000 \\
Reciprocal liking & .641 & 7.359 & .000 \\
\hline
\end{tabular}

Table 9 Regressions for companionship on the male group

\begin{tabular}{|c|c|c|c|}
\hline \multirow[t]{2}{*}{ Variable } & \multicolumn{3}{|c|}{ Companionship } \\
\hline & $\beta$ & $t$ & $p$ \\
\hline Attractiveness & -.096 & 1.058 & .297 \\
\hline Intimacy & .395 & 3.896 & .000 \\
\hline Similarity & -.305 & -3.666 & .001 \\
\hline Reciprocal liking & .387 & 3.788 & .001 \\
\hline
\end{tabular}

Table 10 Regressions for companionship on the female group

\begin{tabular}{|c|c|c|c|}
\hline \multirow[t]{2}{*}{ Variable } & \multicolumn{3}{|c|}{ Companionship } \\
\hline & $\beta$ & $t$ & $p$ \\
\hline Attractiveness & .333 & 2.588 & .013 \\
\hline Intimacy & .464 & 3.604 & .001 \\
\hline Similarity & -.213 & -1.894 & .065 \\
\hline Reciprocal liking & .193 & 1.216 & .231 \\
\hline
\end{tabular}

explained by intimacy $(\beta=.325, t=2.114, p=.041)$ and reciprocal liking $(\beta=.353, t=2.294, p=.027)$. For participants with high prior expectations of the robot's lifelikeness $72 \%$ of the variance in companionship $(F(2,40)=53.903$, $p<.001)$ could be explained by similarity $(\beta=-.391$, $t=-4.487, p<.001)$ and reciprocal liking $(\beta=.641, t=$ $7.359, p<.001)$.

Moreover, when controlling for gender, different regression models were also found for men and women (see Tables 9 and 10). For the male participants, $78 \%$ of the variance in companionship $(F(3,37)=47.499, p<.001)$ could be explained by similarity $(\beta=-.305, t=-3.666$, $p=.001)$, intimacy $(\beta=.395, t=3.896, p<.001)$, and 
reciprocal liking $(\beta=.387, t=3.788, p=.001)$. For the female participants, only $45 \%$ of the variance in companionship $(F(2,42)=19.438, p<.001)$ could be explained by physical attraction $(\beta=.333, t=2.588, p=.013)$ and intimacy $(\beta=.464, t=3.604, p=.001)$.

It was hypothesized that the preconditions for human friendship formation could better explain the variance in the intention to treat the robot as a companion for participants with high prior expectations of the robot's lifelikeness (H1c) and for women $(\mathrm{H} 2 \mathrm{c})$. The results show that the preconditions for human friendship formation were better predictors of companionship for the participants with high prior expectations of the robot's lifelikeness. Therefore, H1c was fully supported. However, the results for gender differences show that the preconditions for human friendship formation were better predictors of companionship for men than for women. Therefore, H2c was rejected.

\section{General Discussion}

The presented study investigated whether individual's gender (male vs. female) and prior expectations of a robot's lifelikeness (high vs. low) influence the effect of preconditions originally identified for human friendship formation on their intentions to treat a zoomorphic robot as a companion. The results show that when people have high prior expectations of the robot's lifelikeness, similar variables to those that explain why people establish relationships with each other are better able to explain their intentions to treat a zoomorphic robot as a companion. These findings provide an indication that individuals might be more likely to initiate relationships with robots following the same rules as those for humanhuman relationships when they have high prior expectations of the robots' lifelikeness. Thus, especially in the case of high prior expectations for a robot's lifelikeness, it may be that human interactions with robots follow the same principles as interpersonal interactions. This means that future research on human-robot interaction should focus primarily on theories of interpersonal communication for the creation of more suitable social behaviors for companion robots.

The results also show that people with high prior expectations of a robot's lifelikeness will evaluate the robot more positively compared with people who had low prior expectations. Thus, robots designed with the intention of providing companionship for human users should have a lifelike appearance, which does not necessarily mean a humanlike appearance. Our result regarding the positive effect of high prior expectations is contrary to previous findings [74] that recommend low prior expectation settings to prevent disappointment in users. Both studies were performed with comparable experimental conditions (low vs. high prior expectations) and used the same robot (the robotic dinosaur
Pleo); however, the evaluation variables differed, which may explain the different outcomes. Peapcke and Takayama [81] asked for the users' general evaluations of the robot, whereas here, the focus was placed on the users' intentions to treat the robot as a companion. A theoretical explanation for our results can be found in the theories of self-fulfilling prophecy [71] and confirmation bias [78]. These two psychological principles together explain why a person may be seen as more competent when one has high prior expectations of that person, because humans often process only evidence that supports our prior expectations. Additionally, the first impression of something that we form often shapes our final appraisal of that object [87]. In our study, the participants were conditioned to either have high or low prior expectations of the robot's lifelikeness, which, in turn, affected their evaluations of that robot after their first interactions with it. These contradictory findings and explanations between our study and that by Peapcke and Takayama [81] indicate that further research is necessary to explore the effect of prior expectations on the various aspects of evaluations of robots. There seems to be a strong focus in human-robot interaction research on new and undiscovered research angles [19]. However, these contradictory findings illustrate that the replication of studies is vital in any field of science because they ensure that the relevant research is a self-correcting system.

Men and women focus on different preconditions for human friendship formation when they evaluate their intentions to treat zoomorphic robots as companions. This result is not surprising, considering that gender differences have also been observed in previous human-robot interaction research $[39,79,94,100]$. The preconditions for human friendship formation were found to be better able to explain why men would initiate companionship with a zoomorphic robot compared with women. Therefore, it could be that women focus on different aspects when evaluating future human-robot relationships. This means that developers of companion robots should be aware of these gender differences in bonding, and men and women may even prefer different designs, in terms of either appearance or behavior, for their companion robots. However, the type of zoomorphic robot used in this study should be considered. Given that Pleo is a dinosaur, it could be that men are more engaged by zoomorphic robots of this particular type than women are. As an alternative explanation, some researchers have already hypothesized that, especially in the early years of human-robot relationships, men may be more likely than women to emotionally bond with robots compared [62]. Nevertheless, especially because the research field of human-robot relationships remains young, further research is necessary to pinpoint the existing gender differences in human-robot relationships. Such research should focus not only on differences in the evaluation of companionship between different types of robots but also on the differences in the variables that may explain 
why men or women are willing to treat a social robot as a companion.

Physical attractiveness seems to be one of the least important preconditions for human-robot relationships, considering that it was only observed to influence women's intention to treat zoomorphic robots as companions. An earlier meta-analysis of the physical attractiveness stereotype suggests that the effect of the 'what is beautiful is good' paradigm is somewhat modest in size and quite variable across studies [32]. This could explain why physical attraction is not strongly important in human-robot relationships.

As stated above, human-robot relationships constitute a relatively new research topic, and further investigation is necessary concerning the various variables that may help to explain people's intentions to treat robots as companions in addition to those addressed in these studies. For example, some studies suggest that loneliness might be one reason why certain people are more willing to treat zoomorphic robots as companions. Zoomorphic robots are equally qualified to reduce loneliness as real pets [6], and lonely people tend to anthropomorphize robots more strongly [35]. For lonely people, these robots are regarded as better than nothing in certain situations [100]. Empirical evidence of the need to belong indicates that people need a certain number of meaningful relationships [9]. Given that these numbers may vary from person to person, an interesting research topic would be to test whether people who feel as though they lack regular and meaningful interactions with others or people who indicate that they feel lonely would be more willing to treat social robots as companions. In short, further investigation into the different variables that help explain people's intentions to treat robots as companions in addition to those measured in the current study is necessary.

\subsection{Limitations}

In every research study, there are certain limitations that must be addressed. First, a zoomorphic robot was used in these studies. Therefore, it is difficult to generalize the present findings to other types of social robots, such as humanoids. Future social robotics research on prior expectations, gender differences and people's intentions to treat robots as companions should further explore the present findings using other types of robots.

Second, the participants in this study were predominantly students, and therefore, generalization suggestions can be made only for young people of the same generation. Future research should further explore the present findings among other user groups, for example, elderly people, considering that socially assistive robots are expected to, among other applications, provide companionship in care contexts [19].

Third, the participants were allowed to interact freely with the robot. We believed that this approach would allow them to explore the possibilities of the robot in their own way and would avoid possible disappointment experienced as a result of failing to achieve a specific task or goal. Although we mostly observed common interactions such as stroking, playing and feeding, this permission of free interaction could have led to different forms of (social) interaction between the two experimental conditions. This, in turn, might have had an effect on the participants' evaluations of the robot. Therefore, to further validate the current results, future human-robot interaction research should further investigate possible differences between the actual interaction behaviors of people with high versus low prior expectations of a robot's lifelikeness.

Fourth, several researchers have criticized the conceptualization of reciprocal liking and similarity. In early research on the similarity attraction hypothesis, interpersonal attraction was measured by means of the construct of reciprocal liking proposed by Byrne [21]. Although this unidimensional construct exhibits a high level of internal consistency and reliability, the potential confusion between affective and behavioral components cannot be ruled out [74]. This measurement failure was caused by a lack of exploration of the relationship among the three components of attitude (e.g., affective, cognitive, and behavioral) in the similarity and attraction literature [12]. Attraction theorists who adopt a multidimensional approach reconsider the conventional linear relationship between similarity and interpersonal attraction. Attitude similarity may not be rewarding in itself [21], but different types of similarity could influence different aspects of interpersonal attraction. Indeed, findings suggest that interpersonal attraction is not merely a single affective response but rather is also a behavioral attraction response, for which attitudes relevant to the social context and interaction goals of the participants could be important [27]. Further investigation into the contextual effect of interpersonal attraction has confirmed that attitudes with regard to the social context and interaction goals are relevant for behavioral attraction but not for affective first impressions [72]. Therefore, future research on human-robot relationships should also address other conceptualizations of similarity, rather than personality similarity alone, and should account for the three components of attitude when measuring similarity or reciprocal liking.

\subsection{Conclusion}

The presented study investigated whether individual's gender (male vs. female) and prior expectations of a robot's lifelikeness (high vs. low) influence the effect of preconditions originally identified for human friendship formation on their intentions to treat a zoomorphic robot as a companion. Our results show that when people have high prior expectations of a robot's lifelikeness, similar variables that explain why 
people establish relationships with each other are better able to explain their intentions to treat such a zoomorphic robot as a companion. Thus, companion robots should have a lifelike appearance, which does not necessarily mean a humanlike appearance. Moreover, men and women focus on different preconditions for human friendship formation when they evaluate their intentions to treat zoomorphic robots as companions. This means that developers of companion robots should be aware of these gender differences in bonding, and men and women may even prefer different designs, in terms of either appearance or behavior, for their companion robots.

Open Access This article is distributed under the terms of the Creative Commons Attribution 4.0 International License (http://creativecomm ons.org/licenses/by/4.0/), which permits unrestricted use, distribution, and reproduction in any medium, provided you give appropriate credit to the original author(s) and the source, provide a link to the Creative Commons license, and indicate if changes were made.

\section{References}

1. Andreoni J, Petrie R (2008) Beauty, gender and stereotypes: evidence from laboratory experiments. J Econ Psychol 29:73-93

2. Archer J (1997) Why do people love their pets. Evol Hum Behav 18:237-259

3. Aronson E, Linder D (1964) Gain and loss of esteem as determinants of interpersonal attractiveness. J Exp Soc Psychol 1:156171

4. Aronson E, Wilson T, Akert R (1994) Social psychology: the hearth and mind. Harper Collins, New York

5. Arras KO, Cerqui D (2005) Do we want to share our lives and bodies with robots. Swiss Federal Institute of Technology Lausanne, EPFL, Lausanne

6. Banks MR, Willoughby LM, Banks WA (2008) Animal-assisted therapy and loneliness in nursing homes: use of robotic vs. living dogs. J Am Med Dir Assoc 9:173-177

7. Bartneck C, Hue J (2008) Exploring the abuse of robots. Interact Stud 9:415-433

8. Bartneck C, Kulić D, Croft E, Zoghbi S (2009) Measurement instruments for the anthropomorphism, animacy, likeability, perceived intelligence, and perceived safety of robots. Int J Soc Robot $1: 71-81$

9. Baumeister RF, Leary MR (1995) The need to belong: desire for interpersonal attachment as a fundamental human motivation. Psychol Bull 117:497-529

10. Bem DJ, Allen A (1974) On predicting some of te people some of the time: the search for cross-sectional consistencies in behavior. Psychol Rev 81:506-520

11. Berg JH (1987) Responsiveness and self-disclosure. In: Derlega VJ, Berg JH (eds) Self-disclosure: theory, research, and therapy. Plenum Press, New York, pp 101-130

12. Berscheid E (1985) Interpersonal attraction. In: Lindzey G, Aronson E (eds) The handbook of social psychology. Random House, New York

13. Berscheid E, Graziano W (1979) The initiation of social relationships and interpersonal attraction. In: Burgess RL, Huston TL (eds) Social exchange in developing relationships. Academic, New York, pp 31-60

14. Berscheid E, Peplau LA (1983) The emerging science of relationships. In: Kelly HH et al (eds) Close relationships. W.H. Freeman, New York, pp 1-19
15. Berscheid E, Reis HT (1998) Attraction and close relationships. In: Gilbert DT, Fiske ST, Lindzey G (eds) The handbook of social psychology. Oxford Press, New York, pp 193-281

16. Bickmore TW, Pickard RW (2005) Establishing and maintaining long-term human-computer relationships. ACM Trans ComputerHuman Interact 12:293-327

17. Blanck PD (1993) Interpersonal expectations: theory, research, and applications. CUP, Cambridge

18. Bornstein RF (1989) Exposure and affect: overview and metaanalysis of research, 1968-1987. Psychol Bull 106:265-289

19. Broekens J, Heerink M, Rosendal H (2009) Assistive social robots in eldercare: a review. Assitive Soc Robots 8:94-103

20. Byrne D, London O, Reeves K (1968) The effects of physical attractiveness, sex, and attitude similarity on interpersonal attraction. J Personal 36:259-271

21. Byrne D, Nelson D (1965) Attraction as a linear function of proportion of positive reinforcements. J Personal Soc Psychol 1:659-663

22. Cacioppo JT, Patrick B (2008) Loneliness: human nature and the need for social connection. Norton, New York

23. Cerulo KA (2009) Nonhumans in social interaction. Ann Rev Sociol 35:531-552

24. Coeckelbergh M (2011) Humans, animals, and robots: a phenomenological approach to human-robot relations. Int J Soc Robot 3:197-204

25. Condon JW, Crano WD (1988) Inferred evaluation and the relation between attitude similarity and interpersonal attraction. J Personal Soc Psychol 54:789-797

26. Dautenhahn K (2002) Design spaces and niche spaces of believable social robots. International workshop on robot and human interactive communication, Berlin

27. Davis D (1982) Determinants of responsiveness in dyadic interaction. In: Ickes W, Knowles ES (eds) Personality, roles, and social behavior. Springer, New York, pp 85-139

28. Denissen JJ, Geenen R, van Aken MA, Gosling SD, Potter J (2008) Development and validation of a Dutch translation of the Big Five Inventory. J Personal Assess 90:152-157

29. Duck SW (1973) Personal relationships and personal constructs. Wiley, New York

30. Duck SW, Spencer C (1972) Personal constructs and friendship formation. J Personal Soc Psychol 23:40-45

31. Eagly AH (1978) Sex differences in influence ability. Psychol Bull 85:86-116

32. Eagly AH, Ashmore RD, Makhijani MG, Longo LC (1991) What is beautiful is good, but..: a meta-analytic review of research on the physical attractiveness stereotype. Psychol Bull 110:109128

33. Eimler SC, Krämer NC, von der Pütten AM (2011) Empirical results on determinants of acceptance and emotion attribution in confrontation with a robot rabbit. Appl Artif Intell 25:503529

34. Epley N, Waytz A, Akalis S, Cacioppo JT (2008) When we need a human: motivational determinants of anthropomorphism. Soc Cogn 26:143-155

35. Eyssel F, Reich N (2013) Loneliness makes the heart grow fonder (of robots): on the effects of loneliness on psychological anthropomorphism. International conference on human-robot interaction, Tokyo

36. Feil-Seifer D, Mataric MJ (2011) Socially assistive robotics. IEEE Robot Autom Mag 18:24-31

37. Fernaeus Y, Håkansson M, Jacobsson M, Ljungblad S (2010) How do you play with a robotic toy animal?: a long-term study of pleo. International conference on interaction design and children, Barcelona

38. Fong T, Nourbakhsh I, Dautenhahn K (2003) A survey of socially interactive robots. Robot Auton Syst 42:143-166 
39. Forlizzi J (2007) How robotic products become social products: an ethnographic study of robotic products in the home. International conference on human-robot interaction, Arlington

40. Fujita M (2004) On activating human communications with pettype robot AIBO. Proc IEEE 92:1804-1813

41. Gere J, MacDonald G (2010) An update of the empirical case for the need to belong. J Individ Psychol 66:93-115

42. de Graaf MMA, Ben Allouch S (2013) The relation between people's attitude and anxiety towards robots in human-robot interaction. International symposium on robot and human communication, Gyeongju

43. de Graaf MMA, Ben Allouch S, van Dijk JAGM (2014) Longterm evaluation of a social robot in real homes. AISB workshop on New Frontier in human-robot interaction, London

44. de Graaf MMA, Ben Allouch S, Klamer T (2015) Sharing a life with Harvey: exploring the acceptance of and relationship building with a social robot. Comput Hum Behav 43:1-14

45. Harbers H (2002) Weak ethics, strong feelings. In: Keulartz J, Korthals M, Schermer M, Swierstra T (eds) Pragmatist ethics for a technological culture. Kluwer Academic, Dordrecht, pp 143149

46. Harris Poll (2007) Pets are 'members of the family' and two-thirds of pet owners buy their pets holiday presents. Retrieved from http://www.harrisinteractive.com/harris_poll/ index.asp?PID $=840$

47. Hazan C, Shaver PR (1994) Attachment as an organizational framework for research on close relationships. Psychol Inq 5:1-22

48. Heider F (1958) The psychology of interpersonal relations. Wiley, New York

49. Hoyle RH (1993) Interpersonal attraction in the absence of explicit attitudinal information. Soc Cogn 11:309-320

50. Jenkins S, Draper H (2015) Care, monitoring, and companionship: views on care robots from older people and their carers. Int J Soc Robot 7(5):673-683

51. Jones SC, Schrauger JS (1970) Reputation and self-evaluation as determinants of attractiveness. Sociometry 33:276-286

52. Kahn PH, Friedman B, Perez-Granados DR, Freier NG (2006) Zoomorphic robots in the lives of preschool children. Interact Stud 7:405-436

53. Kanda T, Sato R, Saiwaki N, Ishiguro H (2007) A two-month field trial in an elementary school for long-term human-robot interaction. IEEE Trans Robot 23:962-971

54. Kerepesi A, Kubinyi E, Jonsson GK, Magnusson MS, Miklosi A (2006) Behavioural comparison of human-animal (dog) and human-robot (AIBO) interactions. Behav Process 73:92-99

55. Kniffin KM, Wilson DS (2004) The effect of nonphysical traits on the perception of physical attractiveness: three naturalistic studies. Evol Hum Behav 25:88-101

56. Krämer NC, Eimler SN, Pütten AM, Payr S (2011) Theory of companion: what can theoratical model contribute to applications and understanding of human-robot interaction? Appl Artif Intell 25:474-502

57. Krämer NC, von der Pütten AM, Eimler SN (2012) Human-agent and human-robot interaction theory: similarities to and differences from human-human interaction. In: Zacarias M, de Oliveira JV (eds) Human-computer interaction. Springer, Berlin

58. Laurenceau JP, Feldman Barrett L (1998) Intimacy as an interpersonal process: the importance of self-disclosure, partner disclosure, and perceived partner responsiveness in interpersonal exchanges. J Personal Soc Psychol 74:1238-1251

59. Leite I, Pereira A, Mascarenhas S, Martinho C, Prada R, Paiva A (2013) The influence of empathy in human-robot relations. Int J Human-Computer Stud 71(3):250-260
60. Leite I, Castellano G, Pereira A, Martinho C, Paiva A (2014) Empathic robots for long-term interaction. Int J Soc Robot 6:329341

61. Levinger G (1983) Development and change. In: Kelley HH et al (eds) Close relationships. WH Freeman, New York, pp 315359

62. Levy D (2008) Love and sex with robots: the evolution of humanrobot relationships. HarperCollins Publishers Inc, New York

63. Libin AV, Libin EV (2004) Person-robot interactions from the robopsychologists' point of view: the robotic psychology and robotherapy approach. Proc IEEE 92:1789-1803

64. Lorenz K (1970) Studies in animal and human behavior (vol. 1) (trans: Martin R). Methuen, London:

65. Lohse M (2011) Bridging the gap between users' expectations and system evaluations. International symposium on robot and human interactive communication, Atlanta

66. MacDorman KF, Cowley SJ (2006) Long-term relationships as a benchmark for robot personhood. International symposium on robot and human interactive communication, Hatfield

67. MacDorman KF, Vasudevan SK, Ho CC (2009) Does Japan really have robot mania?: comparing attitudes by implicit and explicit measures. AI Soc 23:485-510

68. Manago AM, Taylor T, Greenfield PM (2012) Me and my 400 friends: the anatomy of college students' Facebook networks, their communication patterns, and well-being. Dev Psychol 48:369380

69. Messent PR, Serpell JA (1981) An historical and biological view of the pet-owner bond. In: Fogle B (ed) Interrelations between people and pets. Charles C. Thomas, Springfield, pp 5-22

70. McCroskey JC, Richmond VP, Daly JA (1975) The development of a measure of perceived homophily in interpersonal communication. Hum Commun Res 1:323-332

71. Merton RK (1948) The self-fulfilling prophecy. Antioch Rev 8:193-210

72. Michinov E, Monteil JM (2002) The similarity-attraction relationship revisited: divergence between the affective and behavioral facets of attraction. Eur J Soc Psychol 32:485-500

73. Miller JB (1986) Toward a new psychology of women. Beacon Press, Boston

74. Miller GR, Steinberg M (1975) Between people: a new analysis of interpersonal communication. Science Research Associates, Chicago

75. Minton HL, Schneider FW (1980) Differential psychology. Waveland Press, Prospects Heights

76. Mori M, MacDorman KF, Kageki N (2012) The uncanny valley. Robot Autom Mag 19:98-100

77. Newcomb TM (1956) The prediction of interpersonal attraction. Am Psychol 11:575-586

78. Nickerson RS (1998) Confirmation bias: a ubiquitous phenomenon in many guises. Rev Gen Psychol 2:175-220

79. Nomura T, Kanda T, Suzuki T, Kato K (2008) Prediction of human behavior in human-robot interaction using psychological scales for anxiety and negative attitudes toward robots. IEEE Trans Robot 24:442-451

80. Norman DA (1994) How might people interact with agents. Commun ACM 37:68-71

81. Paepcke S, Takayama L (2010) Judging a bot by its cover: an experiment on expectation setting for personal robots. International conference on human-robot interaction, Osaka

82. Perlman D, Fehr B (1987) The development of intimate relationships. In: Perlman D, Duck S (eds) Intimate relationships. Sage Publications, Newbury Park, pp 13-42 
83. Petronio S (2002) Boundaries of privacy: dialects of discourse. State University of New York, Albany

84. Petside.com. (2008) AP-Petside Poll: most owners say they can 'talk' with pets. Retrieved from http://www.petside.com/thesidewalk/news/ap-petside_poll_america_prefers_mutt_over_pu re-bred_for_first_family_pup.php

85. Pew Foundation (2006) Gauging family intimacy: dogs edge cats (dads trail both). Societal Trends Report. Retrieved from http:// pewsocialtrends.org/assets/pdf/Pets.pdf

86. Quin C (2003) The emotional life of objects. J Des Technol Educ 8:129-136

87. Rabin M, Schrag JL (1999) First impressions matter: a model of confirmatory bias. Q J Ergon 114:37-82

88. Reeves B, Nass C (1996) The media equation: how people treat computers, television, and new media like real people and places. CSLI Publications, New York

89. Reis HT, Shaver P (1988) Intimacy as an interpersonal process. In: Duck S (ed) Handbook of personal relationships: theory, relationships and interventions. Wiley, Chichester, p 434

90. Sable P (1995) Pets, attachment, and well-being across the life cycle. Soc Work 40:334-341

91. Sanders C (1993) Understanding dogs: caretakers attributions of mindness in canine-human relationships. J Contemp Ethnogr 22(2):205-226

92. Sandry E (2015) Re-evaluating the form and communication of social robots. Int J Soc Robot 7:335-346

93. Scopelliti M, Giuliani MV, Fornara F (2005) Robots in a domestic setting: a psychological approach. Univers Access Inf Soc 4:146155

94. Schermerhorn P, Scheutz M, Crowell CR (2008) Robot social presence and gender: do females view robots differently than males? International conference on human robot interaction, Amsterdam

95. Serpell J (1996) In the company of animals: a study on humananimal relationships. Cambridge University Press, Cambridge

96. Smith SL (1983) Interactions between pet dogs and family members: an ethological study. In: Katcher AH, Beck AM (eds) New perspectives on our lives with companion animals. University of Pennsylvania Press, Philadelphia, pp 29-36

97. Sun HS, Zhang P (2006) The role of moderating factors in user technology acceptance. Int J Human-Computer Stud 64:53-78

98. Sung JY, Guo L, Grinter RE, Christensen HI (2007) My roomba is Rambo: intimate home appliances. UbiComp 2007 (pp 145-162). Springer, Berlin

99. Taylor D, Altman I (1987) Communication in interpersonal relationships: social penetration processes. In: Roloff ME, Miller G (eds) Interpersonal processes: new directions in communication research. Sage Publications, Newbury Park, pp 257-277

100. Turkle S (2011) Alone together: why we expect more from technology and less from each other. Basic Books, New York

101. Venkatesh V, Morris MG, Davis GB, Davis FD (2003) User acceptance of information technology: toward a unified view. MIS Q $27: 425-478$
102. Vossen S, Ham J, Midden C (2009) Social influence of a persuasive agent: the role of agent embodiment and evaluative feedback. International conference on persuasive technology, Claremont

103. Wada K, Shibata T (2007) Living with seal robots: its sociopsychological and physiological influences on the elderly at a care house. IEEE Trans Robot 23:972-980

104. Waiblinger W (2009) Human-animal relations. In: Jensen P (ed) The ethology of domestic animals: an introductory text. $\mathrm{CAB}$ Publishing, Cambridge, pp 102-118

105. Weinberg D (1997) The social construction of non-human agency: the case of mental disorders. Soc Probl 44:217-234

106. Weiss RS (1982) Attachment in adult life. In: Parks CM, Stevenson-Hinde J (eds) The place of attachment in human behavior. Basic Books, New York, pp 171-184

107. Young JE, Hawkinds R, Sharlin E, Igarashi T (2007) Towards acceptable domestic robots: applying insights from social psychology. Int J Soc Robot 1:95-108

108. Zhang P, Li N (2005) The importance of affective quality. Commun ACM 48:105-108

109. Zilcha-Mano S, Mikulincer M, Shaver PR (2011) An attachment perspective on human-pet relationships: conceptualization and assessment of pet attachment orientations. J Res Personal 45:345357

Maartje Margaretha Allegonda de Graaf is currently a postdoctoral researcher at the Department of Communication Science, University of Twente. Her Ph.D. research on the long-term user acceptance of social robots in domestic environments, defended in June 2015, indicated a strong role of people's anthropomorphic responses to robots in the process of long-term acceptance. Envisioning a future in which the social abilities of robots wil only increase, her current research interest focuses on the user's social, emotional and cognitive responses to robots and the societal and ethical consequences of such responses.

Somaya Ben Allouch received her Ph.D. in 2008 from the University of Twente, the Netherlands where she looked into the subject of the adoption and acceptance of pervasive computing technologies. Her main research interests are: (1) how people adopt and accept technologies in their everyday lives, with a specific focus on ubiquitous computing technologies; (2) the design and use of social robots in people's private environments; and (3) social aspects of information and communication technologies. She has been a visiting researcher at the Ambient Intelligence Research Lab of Stanford University in 2011 and 2012. Somaya is member of the editorial board of the Journal of Ambient Intelligence and Smart Environments. She is currently leading the research group Technology, Health \& Care at the Saxion University of Applied Science in the Netherlands. 